\title{
ADICIONES AL «DICCIONARIO DE LINGÜÍSTICA DE LA ESCUELA ESPAÑOLA» (III) Y A LA «HISTORIA GENERAL DE LA LENGUA ESPAÑOLA» (I)
}

FRANCISCO ABAD

UNED. Madrid

fabad@flog.uned.es

\section{RESUMEN}

En este trabajo se hacen adiciones conceptuales y bibliográficas a las dos obras que se mencionan.

PALABRAS CLAVE: «Escuela española» de lingüística; Historia de la lengua española; Salvador Fernández Ramírez.

\section{RÉSUMÉ}

Dans ce travail nous ajoutons des concepts et une bibliographie spécifique aux deux livres de référence mentionnés.

Mots-CLEF: «École espagnole» de linguistique; Histoire de la langue espagnole; Salvador Fernández Ramírez.

\section{AdiCIONES AL «DICCIONARIO»}

Cuando elaboramos nuestro Diccionario de lingüística de la escuela española, aún no se hallaba editado el volumen póstumo sobre el verbo de la Gramática Española de Salvador Fernández Ramírez, que nada más ha aparecido en la segunda edición de 
la obra. Muerto don Salvador, los profs. José Polo — principalmente-, Ignacio Bosque y Bienvenido Palomo (distinguidos compañeros y buenos amigos los tres desde hace más de treinta años) han puesto en el mercado de nuevo esta Gramática, a la que han incorporado escritos concordantes del autor ya aparecidos en forma de artículo, y en particular lo redactado sobre el verbo, páginas estas últimas cuya edición ha estado a cargo de Bosque; los editores han tenido acceso además a los papeles personales del gramático.

La aludida segunda edición — parcelada en seis volúmenes y publicada entre 1985 y 1991 - nos permite reconsiderar el texto del gramático madrileño e introducir mayor material pertinente en el DLEE. Desde luego según hagamos más estricto el análisis o no, podremos obtener mayor o menor rendimiento de los textos tenidos en cuenta en nuestro léxico; en todo caso hemos pretendido que lo más fundamental no se halle ausente.

El propio José Polo ha manifestado en su libro En torno a la obra científica de Salvador Fernández Ramírez (1998) algunas reservas ante la segunda edición - que él ha capitaneado- de la presente Gramática Española: toda obra humana es perfectible. En relación al volumen 4. El verbo y la oración, ha escrito: «Convendrá realizar en el futuro en dicho volumen algunas mejoras: supresión de erratas, «completar» algunas fichas, tensar algo más la cuerda de la arquitectura y del detalle tipográficos, subsanar pequeños defectos en la redacción de segmentos interpolados, etc.»; por lo que respecta al vol. 5 preparado por el prof. Palomo, manifiesta: podremos - al revisarlo- «corregir algún error, completar algunas fichas y hasta enmendar alguna persistente, por no decir heroica, errata practicada por nuestro gramático»: la de «interpretar mal la consabida sigla $\mathrm{BDH}$ » (no nos parece a nosotros errata la disfunción corriente al entender esa sigla — «Boletín» en vez de «Biblioteca»-, sino error producto de la cita de memoria, error repetido luego por segundos y terceros autores).

Si nuestros compañeros nos lo permiten, transcribimos con ánimo constructivo, cordial y amistoso tres de las observaciones que hemos anotado al leer entera y por su orden la Gramática Española en esta segunda edición.

a) Se preguntaba I. Bosque en el Discurso de su ingreso académico (La búsqueda infinita, 1997) «si don Salvador conocía El arte de la prudencia de Gracián». Cabe responder que sí, pues la obra aparece mencionada varias veces y según su verdadero título (que - como se sabe - es el de «Oráculo manual y arte de prudencia») en el cap. I del volumen 4 de la Gramática Española editado precisamente por el prof. Bosque. El texto El arte de la prudencia es una edición facticia con numerosos cambios que se inician por el del título, una publicación no filológica y de no muy alta divulgación: el propio autor de esos cambios - un profesor de literatura - confiesa y salva su responsabilidad al decir que «siguiendo las directrices de la editorial, [...] se han rehecho frases y se ha modificado la sintaxis, además de sustituir términos»; acaso tal editorial nada más buscó el mismo éxito en el mercado que la obra ha tenido en Norteamérica. Así pues Oráculo manual y arte de prudencia y *El arte de la prudencia son la misma obra.

b) En el volumen final de fuentes de la Gramática resultará de importancia no atribuir al CSIC obras de antes de la guerra publicadas por el Centro de Estudios Históricos de la JAE: el CSIC no fue durante muchos lustros sino la réplica franquista al espíritu y a las personas de esa JAE. En el mismo volumen, a Francisco de Cossío se le atribuye un texto de José María de Cossío. Etc. 
c) Alguna falta de ortografía que se escapó por inadvertencia - a todos nos puede ocurrir - en las ediciones de la Revista de Occidente al imprimirse el volumen I (1951), se halla corregida en la segunda edición de la obra; alguna otra que asimismo se escapó en la primera impresión de uno de los artículos reeditados ahora, está mantenida en cambio en los volúmenes finales de esta segunda edición de la Gramática.

Salvador Fernández Ramírez editó a Lope; conocía muy bien la lengua griega y tradujo tratados sobre esa lengua; abordó problemas de la lírica; escribió de gramática española; etc. Era un humanista completo que con su obra demostró que se identificaba con unas palabras de P. Kretschmer que él mismo puso en castellano y que subrayamos nosotros: «La actividad [investigadora] lingüística, como todas las disciplinas que van a buscar sus fuentes en textos literarios, necesita el instrumento de la filología para la recta comprensión y la interpretación crítica de la tradición idiomática».

$$
* * *
$$

Según decimos, sistematizamos en lo que sigue algunos conceptos y contenidos presentes en las obras de Fernández Ramírez; debe advertirse que en ocasiones damos otra redacción y —en parte - contenido a entradas que ya se hallaban en el DLEE: buscamos de esta manera una visión global de las ideas de don Salvador que resulte coherente.

\section{BIBLIOGRAFÍA MENCIONADA A CONTINUACIÓN}

Alonso, Amado: Estudios lingüísticos. Temas españoles, Madrid, Gredos, segunda ed., 1961.

BÜHLER, Karl: Teoría del lenguaje, Madrid, Alianza, 1979.

FERNÁNDEZ [RAMíREZ], Salvador: «¿Dónde están las palabras?», Analecta Malacitana, XVIII/1, 1995, pp. 175-188.

— «El concepto de forma en Gramática», RUM, VII/26, 1958, pp. 161-173.

- Gramática Española, I, Madrid, Editorial Revista de Occidente, 1951.

- Gramática Española, 1, Madrid, Arco/Libros, 1985.

- Gramática Española, 4, Madrid, Arco/Libros, 1986.

- «Ortega y Gasset, escritor», BRAE, LXIII, 1983, pp. 173-208.

- «Un proceso lingüístico en marcha», PFLE, Madrid, Eds. Cultura Hispánica, MCMLXIV, II, pp. 277-285.

HJelmslev, Louis: Principios de Gramática General, trad. esp., Madrid, Gredos, 1976.

JeSPERSEn, Otto, La filosofía de la gramática, trad. cast., Barcelona, Anagrama, 1975.

Llorente, Antonio, Teoría de la lengua e historia de la lingüística, Madrid, Eds. Alcalá, 1967.

VIVES, Juan Luis, Libro llamado Instrucción de la mujer cristiana traducido de latín en romance por Juan Justiniano, ed., prólogo y notas de Salvador Fernández Ramírez, Madrid, Signo, 1936.

Acusativo de los pronombres personales. En su criterio y procedimiento de enlazar lo sintáctico con lo semántico, distingue Salvador Fernández Ramírez: «El acusativo puede ser externo: A Faustino lo han matao [...] o interno, con valor de contenido: [...] he recibido palos y los he dado [...]; o de resultado: llegó a sostener que el terreno lo hace todo». Nuestro autor maneja en la Gramática los «Principios de Gramática General» de Louis Hjelmslev, en los que tal teórico había postulado efectivamente: «No hay que se- 
parar la expresión y la significación. [...] Sólo hay un procedimiento gramatical posible: investigar la vinculación entre la expresión y la significación, partiendo de la expresión para buscar la significación. [...] Una vez constatada una categoría formal, debemos presumir siempre que tiene un fondo significativo»; de hecho en el «Prólogo» de 1951 tiene expresado este propósito don Salvador: «Mi interés se centra [...] en la naturaleza de los actos psíquicos y en su correlación con las categorías y las formas de expresión». En el texto provisional del «Prólogo» a la segunda edición - que proyectaba - del volumen de 1951 manifiesta de manera muy nítida, haciéndose eco implícito de varias teorías lingüísticas de la primera mitad del siglo XX: «La semántica, con muy buenas razones destronada de la gramática, no puede arrancarse de ella de una manera tan radical como algunos pretenden. En la sintaxis española se dan casos muy especiales en que no existe diferencia formal de estructuras, pero flota en la conciencia lingüística más elemental un más o un menos significativo de tal naturaleza que separa lo que es literalmente idéntico. Y en esos casos no existen en absoluto criterios formales de separación. [...] He reconocido la necesidad de delimitar y analizar con algún rigor de método las diferentes categorías de actos psíquicos, representativos, volitivos y emocionales, que se hallan como soporte de determinadas estructuras y hablo por eso de actos de opción, de actos o estados psíquicos de indiferencia, por ejemplo, para caracterizar incluso determinadas categorías de palabras. Nadie me convencerá de que esta pretensión es ociosa en gramática». Por igual don Salvador tenía escrito: «No se trata de prescindir de las significaciones por completo, sino que se trata, como aconseja Hjelmslev, del procedimiento que consiste en ir de la forma al pensamiento y no al revés. Si nos hallamos con una relación o con una estructura que encuentra su explicación en sí misma sin necesidad de que la apoyemos en ningún contenido semántico, habremos seguido en nuestra investigación un principio formal».

Bibliografía: Gramática Española, I, pp. XIV y 191; Gramática Española, 1, pp. 315-316; «El concepto de forma en Gramática»; L. Hjelmslev, Principios de Gramática General, pp. 96-97 y 175.

Adjetivo. Jespersen [lo veremos nosotros luego, F. A.] «llama nombres sustantivos a los que funcionan ordinariamente como término principal o primario, adjetivos a los que funcionan ordinariamente como elemento adjunto o secundario».

Bibliografía: Gramática Española, I, p. 98.

Agrupación normal y anómala. «Llamamos agrupación normal a aquella que realizan normalmente cosas y personas y agrupación anómala a una agrupación accidental incapaz de establecer un campo ['ámbito', 'espacio'] de sentido en el enunciado. Las agrupaciones normales [...] son de tal naturaleza para la conciencia lingüística que el solo enunciado de uno de los elementos del grupo [ ...] basta para establecer un campo de sentido. La inducción de sentido que se produce en el campo se revela en el hecho de que el reemplaza a un, e inversamente, en el caso contrario de una agrupación anómala. Así se explica la variación: se quitó el sombrero y sacó un sombrero de la caja del piano. [... Decir en otro caso sobre la silla cuando no se ha hablado antes para nada de esa silla] es operar con los elementos que están presentes en la fantasía, en una conexión de imágenes que tiene su correlato en el campo de sentido del contexto».

Bibliografía: Gramática Española, I, p. 281. 
Agrupaciones indisolubles con el adjetivo. «Existen con el adjetivo agrupaciones que podemos denominar indisolubles, es decir, locuciones que son correlativas de un concepto y que no se pueden enunciar parcialmente sin alterar el objeto de la mención: Semana Santa, pena capital».

Bibliografía: Gramática Española, I, p.140.

Alopatía. «La idea de que algo viene de fuera a afectarnos o a afectar a una tercera persona la ponen de relieve algunos enunciados en los que se dan parejas de verbos para designar acciones recíprocas: la que se realiza, la que se padece»: Donde las dan las toman. [...] «Podríamos designar esta situación con el término alopatía, que no es extraño a la lingüística» (Apolonio Discolo).

Bibliografía: Gramática Española, 4, p. 120.

Anticipación descriptiva del verbo. Trata Fernández Ramírez de la colocación del sujeto tras el verbo, y enuncia cómo «la inversión absoluta es muy frecuente en español cuando se trata de representar sonidos, olores y en general percepciones típicas: 'Batía un tambor, tecleaba un organillo'. Y comprueba además que [... en otras situaciones] «el valor descriptivo reside sustancialmente en el verbo, el sujeto aparece en un segundo plano de la percepción, de tal manera que la organización sintáctica se corresponde en el orden real y objetivo de las percepciones [...]. Podemos hablar, por consiguiente, de una anticipación descriptiva del verbo: 'Cubrían las ventanas cortinones de encaje poco tupido' [...] 'Traspasaba su mirada'».

Bibliografía: Gramática Española, 4, p. 445.

Artículo de tipo o arquetipo. «En la lengua literaria sobre todo - percibe don Salvador - aparece algunas veces el artículo, que nos presenta el concepto asumiendo determinadas cualidades excepcionales, como encarnación de un tipo o arquetipo. El artículo equivale en estos casos a una reducción de uno de esos: La viuda era l a mujer seria que prefiere que las cosas sucedan en silencio».

Bibliografía: Gramática Española, I, p. 278.

Artículo, la falta de. «La falta de artículo y de pronombre destaca también la dimensión cualitativa de las cosas, o más bien desactualiza el concepto y lo presenta en su pura esencia. Podríamos distinguir, entre las diversas maneras de este empleo, fórmulas hiperbólicas de encarecimiento: Nunca vi espectáculo más lastimoso [...]; fórmulas reforzadas por la anteposición del predicado, del sujeto o del complemento directo: Dechado de actividad y sagacidad en el cultivo de la noticia fué Mencheta»; «y otras fórmulas [...]. Las formulas con un, en cambio, presentan las cosas en su realidad sensible».

Nuestro autor remite específicamente a unas páginas de Amado Alonso en las que el filólogo hispano-argentino (queda apuntado en el DLEE) había dicho: «Echando mano de la pareja de conceptos filosóficos esencia-existencia, diremos que el nombre con artículo se refiere a objetos existenciales y sin él a objetos esenciales. Con artículo, a las cosas; sin él, a nuestras valoraciones subjetivas y categoriales de las cosas. [...] El nombre sin artículo apunta directamente a la esencia de lo nombrado, a nuestra valoración subjetiva del objeto, a su rango [...].La ausencia de artículo corresponde al carácter puramente cua- 
litativo con que el objeto es nombrado; denuncia una referencia al quid o esencia del objeto ».

Bibliografía: Gramática Española, I, pp. 278-279; A. Alonso, Temas españoles, pp. 134,135 y 137.

Campo de sentido. Don Salvador Fernández no resulta suficientemente explícito, pero - en su uso - parece hacer equivaler el significado de la lexía «campo de sentido» al de 'contexto verbal de significaciones', y de esta manera habla más de una vez de «el campo de sentido del contexto», o asimismo de «nexos de sentido» en el decurso; por nuestra parte parafraseamos campo de sentido por 'ámbito de significaciones'. Otras veces nuestro autor habla de «campo simbólico» o (entendemos) 'significativo'. Desde luego Bühler - en quien asimismo se fundamenta nuestro gramático- había definido: «Los nombres funcionan como símbolos y reciben su impleción y precisión significativa específica en el entorno sinsemántico; propongo el nombre de campo simbólico para este otro orden [además del orden del campo mostrativo ...]. El campo simbólico del lenguaje en el producto lingüístico compuesto proporciona una segunda clase de recursos de construcción y comprensión, que se pueden reunir bajo el nombre contexto».

Bibliografía: Gramática Española, I, pp. 99, 101, 144, 242 y 281; K. Bühler, Teoría del lenguaje, pp. 100 y 167.

Campo sinfísico. De igual manera nuestro autor da por sabido lo que se ha de entender en tanto «campo sinfísico»: «Es también antiguo el uso de[1 troquel] el presente agrupado con un término para la referencia al campo sinfísico: En l a p r e s e $n$ t e edición hemos colocado al final la bibliografía». Bühler a su vez tenía expuesto acerca de lo que tipifica como 'adscripción objetiva': «Es común a la clase entera de empleos de nombres que consideramos aquí la adscripción objetiva; proponemos el nombre sinfísico para esta inclusión. [... El lector debe pensar] al leer "entorno sinfísico», en «adherencia"».

Bibliografía: Gramática Española, I, pp. 265-266; K. Bühler, Teoría, p. 177.

Catafórico. «Utilizamos alguna vez — advierte Fernández Ramírez - el término catafórico, propuesto por Bühler, para la referencia anticipadora»; efectivamente Bühler escribió: «Decimos nosotros referencia retrógrada y referencia previa (o retrospección y prospección). [... Habría que buscar la palabra] catáfora» para esa referencia previa.

Bibliografía: Gramática Española, I, p. 208; K. Bühler, Teoría, p. 140 n.

Constantes. «Los elementos de la naturaleza [...] constituyen lo que podríamos llamar c o n s t a n t e s y entran frecuentemente en el discurso en primera mención asociados al artículo: Josefina fue a acomodarse en el césped».

Bibliografía: Gramática Española, I, p. 282.

Deixis. En sucesivas ocasiones alude Salvador Fernández Ramírez a la deixis, e. gr. - de manera general - : «Distingue Bühler el campo demostrativo, en el que se produce la "demonstratio ad oculos" (deixis), el campo del contexto o campo sintáctico que produce una especie de demonstratio reflexiva (anáfora) y agrega todavía a su sistema una deixis que él llama anamnéstica o más específicamente deixis de la fantasía [...]. No- 
sotros emplearemos aquí [la Gramática Española] algunas veces el término deixis como término genérico que abarca las tres especies, pero precisando siempre la naturaleza del campo al que se hace el señalamiento». Y escribe de esta manera consecuentemente: «La deixis anafórica es, pues, una referencia al campo sintáctico del que se hace uso porque coloca a nuestro alcance el único dato sensible (la palabra) de que se dispone en un momento dado para producir la evocación».

En otros párrafos apunta de manera más específica: «Los pronombres personales realizan una especial deixis sensible - la idea de la deixis de los pronombres personales ha sido desarrollada por Bühler [...]—, es decir, un señalamiento extraño al campo simbólico y sintáctico del lenguaje. En nominativo, coinciden en dicha función con las desinencias personales del verbo. Por eso constituyen un verdadero morfema cuando las desinencias son indiferenciadas». En cuanto a Bühler escribió - por ej. - : «Todo lo que es lingüísticamente deíctico coincide en que no recibe en cada caso su impleción y precisión significativa en el campo simbólico, sino en el campo mostrativo del lenguaje; y sólo en él puede recibirla».

Bibliografía: Gramática Española, I, pp. 207, 241 y 249; K. Bühler, Teoría del lenguaje, p. 99.

Denominación. En el caso de «los nombres de aquellas cosas que además de la mención nominal apelativa que les corresponde por razón de la especie a que pertenecen (día, monte, lugar [...]) reciben una denominación especial y distinta (Manzanares, Guadarrama, etc.)», «a este segundo nombre, que puede ser un nombre apelativo o un nombre propio, le llamaremos en adelante d e $\mathrm{n}$ o $\mathrm{m}$ i n a c i ó n» [obsérvese este último leísmo de cosa usado por nuestro autor, que era madrileño - si es que no pertenece al tipógrafo-]. En particular ocurre que «el nombre (común o genérico) y la denominación (nombre propio) se yuxtaponen, como en el río Manzanares o se articulan mediante la preposición de, como en la cumbre de Peñalara [...]. Especialmente en el primer caso, pero también algunas veces en el segundo, el nombre suele imponer su artículo a la denominación cuando se emplea sola: el (río) Manzanares, el (desierto de ) Sahara», etc.

Bibliografía: Gramática Española, I, pp. 152 y 299-300.

Diátesis ingresivo-estativa. «Cuando el complemento predicativo de quedarse es un participio en - $d o$, lo que en realidad se designa con la perífrasis es el estado que resulta del cambio o del proceso a que se refiera el concepto verbal del participio [...]. Es, pues, ésta una diatesis verbal que podríamos llamar ingresivo-estativa», como en 'y su nombre, Eufrasia, quedó grabado en mi memoria'».

Bibliografía: Gramática Española, 4, p. 408.

Eferencia pronominal. Estamos ante otro de los casos en que nuestro autor hace uso de una noción que da por sabida y no ha definido; escribe - por ej._- «Algunos pronombres [...] insisten más bien en una mención nominal anterior [...] o aluden a algo que está presente en la conciencia y en la situación, de tal manera que se trata [...] de lo que podríamos llamar deducción o e f e r e $\mathrm{n}$ c i a», y registra ejemplos como quedó también huérfano de padre. E s te tenía una hermana o Fuera ese abrigo. «La eferencia -escribe asimismo en otros momentos - la realizan también los pronombres demostrativos»; 
«los relativos reproducen por eferencia»: así «el relativo es el pronombre anafórico más caracterizado [...]. Realiza una reproducción por eferencia idéntica e intrínseca». En el DRAE inmediatamente anterior a esta Gramática se define eferente como 'que lleva'; desde luego los relativos significan indirectamente.

Por otra parte y en la conferencia publicada póstumamente «La categoría de pronombre» indicaba nuestro autor $-\mathrm{y}$ no lo acabamos de entender bien - : «He propuesto el término, que no es muy bonito, de eferencia para estos casos en que el señalamiento [pronominal] no aparece orientado [como en este-aquel]».

Cfr. aquí asimismo Referencias de identidad y referencias de no identidad.

Bibliografía: Gramática Española, I, pp. 330-331 y 336; Gramática Española, 1, pp. 281-282.

En pleonástico. SFR toma la denominación de Rufino José Cuervo, y expone y ejemplifica: «En donde se emplea con el mismo valor que donde, aunque mucho menos frecuentemente: Cuando el sitio en donde están acampados [...]. Este en pleonástico (como lo llama Cuervo) obedece probablemente al hecho de que el adverbio donde y los pronombres se emplean, además, con otras preposiciones comunes».

Bibliografía: Gramática Española, I, p. 355.

Estilística. El joven Fernández Ramírez postulaba cómo «hoy no pueden ya satisfacernos estos cuerpos de materiales [gramaticales] en que [...] se desdeña la interpretación estilística». Y en concreto define: «Por estilística entendemos la posibilidad del uso libre de un instrumento lingüístico, manejado con intenciones estéticas o expresivas».

Bibliografía: RFE, XXII, 1935, pp. 73-74; Gramática Española, I, p. 276.

Forma. Fernández Ramírez parafrasea diferentes acepciones que se han dado al término forma, y va enumerando las de 'miembro de un paradigma flexivo'; 'todas y cada una de las variaciones que adopta una palabra en la historia de una lengua'; 'todas las unidades fonéticas que se remontan a un sonido común originario o con las alternancias vocálicas indoeuropeas'; 'morfema'; 'las relaciones de dependencia que establecen los accidentes gramaticales'; 'todo lo que es elemento significativo'; 'la lengua' en el sentido de Saussure. Escribe también: «Signo lingüístico es para Hjelmslev el maridaje de dos formas, por un lado la forma del contenido, por otro lado la forma de la expresión (sustancia del contenido es el mundo de las significaciones [...])». De nuestra parte creemos que este concepto de sustancia del contenido se concibe mejor si designamos con él 'lo real, el mundo, lo referido'.

Bibliografía: «El concepto de forma en Gramática», passim.

Fórmulas perifrásticas de relativo. «Los dos relativos personales quien y el que alternan también, sin antecedente, en ciertas oraciones con el verbo ser, que son fórmulas perifrásticas en las que se resuelven las oraciones de predicado verbal o nominal cuando se trata de insistir, de una manera terminante y que no deje lugar a dudas, en la idea de que la persona o personas mentadas por alguno de sus elementos nominales o pronominales son precisamente aquellas a las que conviene la aseveración contenida en el enunciado y no a otras. Por ejemplo: vosotras podéis alejarle se resuelve con la perífrasis en: 
vosotras sois las que podéis alejarle. [...] De manera que la mención personal se duplica en la perífrasis: una en su forma originaria (vosotras), otra [...] en forma de antecedente del relativo, expreso en las (que)»

Bibliografía: Gramática Española, I, pp. 364-365.

Función apelativa del lenguaje. «Lo que distingue a los interrogativos frente a los demás pronombres - escribe don Salvador - es el hecho de que sirven como instrumentos a la función apelativa del lenguaje. El elemento de la apelación en este caso consiste en una intención inquisitiva, de manera que realizan una referencia catafórica, idéntica y en general intrínseca como los relativos, a la palabra o al concepto inquirido, es decir, a la respuesta». Según es sabido, Bühler proclamó cómo el signo lingüístico es «señal en virtud de su apelación al oyente»

Bibliografía: Gramática Española, I, p. 337; K. Bühler, Teoría, p. 48.

Laísmo. Se trata de «el uso de la por la forma etimológica de dativo le para la mención de persona o de cosa del género femenino».

Bibliografía: Gramática Española, I, p. 201.

Leísmo. «La forma etimológica de dativo del pronombre de $3^{\mathrm{a}}$ persona le [...] penetra profundamente en algunas épocas y en algunos territorios en la función de acusativo masculino, haciendo grave competencia a lo. El fenómeno es antiguo y aparece en los primeros monumentos literarios. Cuervo [...] ha señalado a Madrid y sus provincias circunvecinas como centro del movimiento leísta y los siglos XVI y XVII como su momento culminante».

Bibliografía: Gramática Española I, p. 196.

Método inductivo. Manifestaba nuestro autor al inicio de esta Gramática Española: «Esta obra pretende ser una Gramática descriptiva del español común actual. A ella he aplicado un método inductivo, que es el preconizado por Hjelmslev [...]. Los principios teóricos y las categorías han sido, por consiguiente, comprobados y establecidos a la vista del material en el curso de su manipulación [...] En ningún momento forman parte del material construcciones de mi propia inventiva. La lengua sirve a todas las necesidades comunicativas, expresivas y apelativas del hombre, menos a las reconstrucciones artificiales de los gramáticos». En efecto los Principios de gramática general hjelmslevianos proclaman: «Si existiese realmente una ciencia independiente que se ocupase de los hechos del lenguaje, su único método admisible deberá ser el método empírico. Las categorías que constituyen el sistema de esta ciencia deben establecerse según un método inductivo».

Bibliografía: Gramática Española, I, pp. XVI y XVII 1; L. Hjelmslev, Principios de Gramática General, p. 47.

Modales, usos. «En general, el indicativo presenta las acciones como un producto de la observación y la experiencia, el subjuntivo como eventualidades por ocurrir» (SFR).

Bibliografía: Gramática Española, 4, pp. 385-386. 
Neologismos en Ortega. «Si empleaba neologismos - expone don Salvador-, eran palabras que él acuñaba según los principios más naturales de derivación de la lengua española, como cuando dice reviviscencia, palabra calcada sobre $\mathrm{r}$ e $\mathrm{m}$ i $\mathrm{n}$ i s c e $\mathrm{n}$ $\mathrm{c}$ i a; o partidajes, recordando $\mathrm{m}$ a $\mathrm{r}$ i d a j e s; o petrefactos, 'hechos de piedra', pensando en $\mathrm{p}$ u t r e f a c t o s; o mentefacturas junto a $\mathrm{m}$ a $\mathrm{n} \mathrm{u} \mathrm{f}$ a $\mathrm{c} \mathrm{t} \mathrm{u} \mathrm{r}$ a s».

Bibliografía: «Ortega y Gasset, escritor», p. 188.

Nombre abstracto. «Empleamos en general la denominación de nombre a b s t r a c t o cuando la significación se refiere a un objeto que es parte no independiente de un todo».

Bibliografía: Gramática Española, I, p. 129.

Nombres de sustancia. «Hay que distinguir los nombres de cosas que se pueden contar o son seriables de los nombres de sustancias o magnitudes extensas o intensas. [...] Los segundos (II) se emplean en singular con la significación de toda la sustancia o magnitud o de una cantidad más o menos determinada de ella. Así tenemos por ejemplo: $h a$ bía ríos de mermelada».

Bibliografía: Gramática Española, I, p. 171.

Número poético. Describe don Salvador: «Se emplean singulares genéricos, remedando deliberadamente a veces usos vulgares o una determinada jerga profesional»: Baila el garbanzo en mi caja, La lenteja en mi bolsillo. «Abundan en algunos autores el plural de nombres abstractos, especialmente de cualidad, para designar los objetos que son el soporte de esas cualidades: y él reclinado en $s$ u $a v i d$ a d e s: damascos, sedas, terciopelos [...] El objeto poético tiene también sus exigencias. La visión lírica descompone un fenómeno, una realidad en diversas calidades y momentos, su interés se halla atento a esa multiplicidad. Es frecuente este proceso con los elementos de la naturaleza»: Choques de pasmos Deslumbran a unos c i e l o s Fugados que se huyen; Salir, por fin, salir A g l o r i a s, a r o c í o s (Jorge Guillén). Obsérvese que por errata de imprenta o por una concordancia ad sensum, aparece abundan en vez de abunda.

Bibliografía: Gramática Española, I, pp. 184-185.

Oposición diferencial. «El paso de una palabra de una categoría a otra [en el número] - propone nuestro autor este concepto - supone variaciones más o menos sensibles de significación. [...] El nombre que designa una pasión, un estado de ánimo, una capacidad, pasa a designar objetividades en plural: interés intereses; bien bienes; imaginación imaginaciones; locura locuras».

Bibliografía: Gramática Española, I, pp. 180-181.

Oraciones de relativo. «Desde la Gramática de Bello, la doctrina española distimgue entre oraciones de relativo especificativas y explicativas. Bello las denomina también "subordinadas" e "incidentes"». Nuestro autor analiza además las «oraciones de relativo en enunciados existenciales» $\mathrm{u}$ «oraciones relativas de existencialidad» $\mathrm{y}$ señala cómo se producen «oraciones negativas de existencialidad [...] que en gran número de casos resultan suscitadas por sentimientos de decepción, de dolor, de ironía, etc.», e. 
gr. : no vi nada que valiera la pena; en cuanto a bromas, no ha nacido todavía quien me las dé.

Bibliografía: Gramática Española, I, p. 340; 4, pp. 371 y 374.

Oraciones nominales (taumáticas). «Se entiende en general por oraciones nominales oraciones que no poseen el verbo en forma personal y que consisten sustancialmente en un nombre (sustantivo o adjetivo) o en una forma nominal del verbo». Cuando «el principal sentimiento subyacente» en algunas de estas oraciones «es la admiración o el entusiasmo ante el objeto contemplado», «las [...] denominamos t a u m á t i c a s»: « Vagos paisajes de la tarde, sobre el pueblo! / Campos verdes, con nubes amarillas y rojas, / [...] ¡Limpidez de las brisas entre las casas sórdidas!».

Bibliografía: Gramática Española,4,pp. 493 y 504-505.

Palabra, la. «El concepto de palabra [...] y todas las restantes categorías lingüísticas son partes y miembros de esa entidad abstracta y racional que es el sistema, la lengua [...] El hombre ha conseguido en el lenguaje una desmembración del mundo en fragmentos abstractos - las palabras - y al mismo tiempo una construcción a fondo del mismo mundo: la frase».

Bibliografía: «¿Dónde están las palabras?»,pp. 182-183.

Partes de la oración, Las. Repite y comenta don Salvador: «Es pronombre el término que actúa, en contraste con los nombres, o bien indistintamente como término como término y secundario, o bien exclusivamente como primario o secundario. [...] Hay quien piensa que solo el terreno sintáctico es el que puede darnos los criterios necesarios y suficientes para la determinación de las partes del discurso».

Bibliografía: Gramática Española, 1, p. 285.

Pasiva dinámica española. «En líneas generales podemos afirmar lo siguiente: la acción iterativa o habitual, el enunciado de validez general, el objeto (sujeto pasivo) interno, determinadas formas modales [...] son factores que determinan en la mayoría de los casos el uso de la pasiva refleja. En cambio la acción singular y el objeto (sujeto pasivo) externo determinan a su vez el empleo de la pasiva dinámica»: «Hace falta que su función sea excitada, que trabaje y se canse para que pueda nutrirse»; «Llegó la noche y la función de la Marquesa era preparada con mucha actividad»; «iTodo ha sido descubierto!». «La pasiva dinámica deriva, pues, toda su fuerza representativa y expresiva de la estrecha relación en que la acción del verbo se halla con un agente mentado o no mentado, pero operante con su intención, circunstancia que se intensifica cuando el proceso es momentáneo y cuando el agente se halla desdoblado frente a la porción de la realidad sobre la cual opera, es decir, cuando el objeto directo de su actividad es algo que tiene existencia por sí mismo, es un objeto externo. [...Pero la pasiva dinámica española] utiliza otras fórmulas, sobre todo con los verbos imperfectivos. Agrupa con el participio, en vez del verbo ser, verbos de percepción en forma reflexiva: verse, sentirse, hallarse, etc.: 'Solemos llamar vivir a sentirnos empujados por las cosas en lugar de conducirnos con nuestra propia mano'».

Bibliografía: Gramática Española, 4,pp. 419 y 421-422. 
Persona gramatical, la. Entre más cosas, nuestro autor escribe sobre la persona: «El morfema de tercera persona [...] no realiza en ocasiones ninguna clase de referencia textual o extratextual (amanece). Esta particularidad, unida a la doble capacidad de la $3^{\mathrm{a}}$ persona para actuar en la deixis textual y en la sensible, es la que, en el sistema español de las personas verbales, sitúa a la tercera en oposición a la primera y a la segunda»

Bibliografía: Gramática Española, 4, p. 26.

Personas generales, las. «Las personas verbales y pronominales sin auxilio de otros medios, señalan a veces por sí al hombre en general o al hombre en una situación dada. Hablamos entonces de personas generales. [...] La persona nosotros empleada con referencia al hombre en general es una de las más frecuentes en español. [...:] ¿¿Qué es lo real, lo que vemos o lo que somos?' [...] No sólo la desinencia verbal - mos sino todos los miembros del paradigma de la persona nosotros pueden señalar al hombre en general: '¡Qué destino el nuestro, Dios Santo' [...]. Menos veces se emplea una persona general vosotros, con una intención muy semejante a la de nosotros [...] 'Cuando salís de la estación, un tropel de mozos, de intérpretes, de maleteros os coge el equipaje'». Etc.

Bibliografía: Gramática Española, 4, pp. 42 y ss.

Plural de autor. «El plural de autor — explica SFR - , de tradición clásica, no es extraño a ninguna de las lenguas herederas de esta tradición y sean cuales fueren las últimas motivaciones, mal conocidas, que lo hacen preferible al yo: solemnidad, efusión, modestia, etc., parece inseparable de determinados géneros y situaciones. He aquí algunos ejemplos del s. XX: 'Por nuestra parte, si hemos de ser sinceros, sólo hallamos en su encantadora fisonomía un vicio que es, a la vez, una gran inelegancia' (Ortega y Gasset)».

Bibliografía: Gramática Española, 4, p. 30.

Positivismo decimonónico. En una de las versiones de una conferencia, don Salvador tenía escrito - aunque tachado luego - en sus papeles, y en referencia al buen uso normativo del hablar: «En cuestiones idiomáticas me siento un poco arrastrado más allá de las corrientes positivistas del siglo pasado, corrientes que daban carta de naturaleza a todas las manifestaciones del lenguaje, y yo prefiero [...] la norma [lingüística] a la anarquía».

Bibliografía: «Ortega y Gasset, escritor»,p. 188.

Preguntas pronominales. «El desacuerdo entre la conducta, el pensar o el sentir de alguien y la situación o lo que de ella se conoce, produce sentimientos de extrañeza, de perplejidad, de irritación, etc., y mueve a formular una pregunta para tratar de esclarecer la aparente paradoja. Propondría, pues, para ella el nombre de pregunta $\mathrm{p}$ a r a d ó j i c a»: ¿Quién pudo decírtelo, si lo decidí esta noche? [...] En otros casos la contradicción no se formula o se reducen sus términos objetivos al acaecimiento de un hecho imprevisto en desacuerdo con el cumplimiento normal de nuestras expectativas vitales»: «¿Quién tiene esta entonación tan dulce, $\tan$ suave, tan acariciadora?». En esta modalidad y en poesía lírica se acerca «a la que podríamos llamar pregunta e n i g m á t i c a».

Prosigue por igual nuestro autor: «Las preguntas d u b i t a t i v a s buscan una solución a problemas prácticos y de la voluntad, pero no se hallan muy lejos de las enig- 
máticas [¿Dónde lo dejo? ...] Tienen también carácter monologuizante y están desprovistas de expectativa las preguntas e v o c a d o r a s: El coche corre ruidoso por las callejas, dando vaivenes. ¿Por delante de qué casas, de qué vetustos y ruinosos palacios, de qué conventos pasamos?'».

Bibliografía: Gramática Española, 4, pp. 482-484.

Procesos lingüísticos en marcha. A propósito de unos casos concretos que analiza, discurre y teoriza don Salvador: «La inestabilidad que advertimos dentro de un determinado cuadro fonológico, morfológico o gramatical de una lengua suele ser indicio de un reajuste, de una fase de transición entre dos sistemas. Sin embargo la realidad histórica nos hace ver que estas sucesivas etapas no se presentan siempre de una manera tan esquemática; que no hay por lo regular en las diversas trayectorias de una lengua una estación de salida y otra estación de llegada, como límites fijos de cierto movimiento, sino más bien vectores que se montan y encabalgan unos sobre otros. Antes de cumplirse lo que podía ser término del proceso, comienza otro dentro del mismo cuadro o sistema, implicando en él en ocasiones nuevos elementos. A veces estas aparentes fases de inestabilidad se prolongan durante mucho tiempo, sin dejarnos entrever siquiera el término del proceso. Algo de esto último ocurre en español desde los orígenes o casi desde los orígenes de la lengua, con algunos fenómenos como las construcciones con estar, la flexión de los pronombres personales, el empleo de $a$ con el complemento-objeto, etc.».

Bibliografía: «Un proceso lingüístico en marcha», p. 277.

Pronombre, el. «La doble posibilidad — define Fernández Ramírez — de actuar o bien indistintamente como término primario o secundario o exclusivamente en una u otra función es la propiedad formal que caracteriza a los pronombres frente a los nombres, dotados por su parte de la capacidad de actuar preferentemente en una u otra de esas funciones. [...] Podemos considerar la categoría del pronombre como un grupo nominal de semantemas caracterizados por el doble hecho de que actúan indistintamente como término primario y secundario o exclusivamente en una u otra función. Se hallan en el segundo caso los pronombres personales, que sólo funcionan como término primario y los posesivos, que sólo funcionan como término secundario. En el primer caso se encuentran todos los demás pronombres. Frente al nombre, los pronombres poseen una capacidad específica de referencia al campo sintáctico». Por igual nuestro autor ha manifestado: «Que todos los pronombres incluidos por mí dentro de la categoría, incluso los numerales, se apoyan, en determinadas condiciones, en el contexto, y aluden, se refieren o remiten a nombres o pronombres ya enunciados o anticipan los que van a serlo, es algo que nadie podrá discutirme. [...] Que la alusión existe es algo indiscutible. [...] Los indefinidos de una manera especial, y en general los pronombres cuantitativos, incluyendo entre ellos los numerales [...] dejan de apoyarse manifiestamente en el contexto en determinadas condiciones, es a saber, cuando actúan como términos secundarios agrupados con un nombre sustantivo. Nosotros podríamos, naturalmente, desglosarlos en estos casos de la categoría [...]. Podemos optar».

Bibliografía: Gramática Española, I, pp. 237-238 y 329-330; Gramática Española,1, pp. 281-282. 
Pronombres de existencialidad. «Como [los interrogativos] —escribe nuestro autor-, presuponen los indefinidos un problematismo acerca de la existencia de un objeto o de una serie de objetos más o menos conocidos o consabidos, al mismo tiempo que están privados, frente a ellos, de la función apelativa. Por ese dato específico que da coherencia al sistema de los indefinidos podrían recibir la denominación de pronombres de e $\mathrm{x}$ i s t e $\mathrm{n}$ c i a 1 i d a d»: experimentaba una sensación de orgullo cuando algún sacerdote amigo le decía a la puerta de la iglesia: ;De pronto se oye ruido. Alguien se acerca.

Bibliografía: Gramática Española, I, pp. 392-394.

Pronombres interrogativos. «Lo que distingue a los interrogativos frente a los demás pronombres, es el hecho de que sirven como instrumentos a la función apelativa del lenguaje. El elemento de la apelación en este caso consiste en una intención inquisitiva, de manera que realizan una referencia catafórica, idéntica y en general intrínseca como los relativos, a la palabra o al concepto inquirido, es decir, a la respuesta».

Bibliografía: Gramática Española, I, p. 337.

Pronombres personales adjetivos. «Si frente a los demás pronombres — desarrolla nuestro autor - que poseen naturaleza sustantiva y adjetiva, los personales son exclusivamente sustantivos, los posesivos por su parte son exclusivamente adjetivos, aunque se someten, en general, a la misma clase de sustantivaciones que los nombres adjetivos. Por lo que no habría inconveniente en considerarlos como pronombres personales adjetivos. Son, en realidad, formas derivadas de los pronombres personales, como dice Hermann Paul».

Bibliografía: Gramática Española, I, p. 227.

Pronombres relativos. «El relativo es el pronombre anafórico más caracterizado. Realiza una reproducción por eferencia idéntica e intrínseca. Lo que distingue al relativo en general frente a los demás pronombres y en particular frente a los otros anafóricos es el hecho de que, simultáneamente a su actuación como anafórico en el campo sintáctico, desempeña una función de nexo en la articulación hipotáctica. Como anafórico, su papel dentro de los tres órdenes de la rección es casi siempre el de término primario, generalmente sin adjuntos. Pero como nexo hipotáctico, introduce oraciones de segundo grado que son equivalentes de un término secundario». En efecto el relativo «es un anafórico que, frente a otros, tiene la capacidad de actuar como nexo en la hipotaxis».

Bibliografía: Gramática Española, I, pp. 336-337; Gramática Española,1, p. 283.

Renacimiento, el. En tanto marco en el que entender cuestiones sobre el lenguaje que se plantearon al final de nuestro Cuatrocientos y en el Quinientos, ayuda también esta aguda observación de don Salvador: «En el escenario en que se mueve la actividad de Vives, el Renacimiento deja de ser una posición de minorías y se incorpora a los vagos anhelos populares y nacionales, promoviendo una extensa transformación política y religiosa».

Bibliografía: Prólogo a J. L. Vives, Libro llamado Instrucción de la mujer cristiana, p. 10 . 
Referencias de identidad y referencias de no identidad. Don Salvador analiza los pasajes «se acercaron al dueño cuando éste bajó al zaguán»; «no digo tolerancia porque tal vocablo no cuadra en este caso»; «el hombre nuevo y el antiguo» o «numerosas cornucopias - algunas de gran valor - en las paredes», y delimita: «Hay, pues, referencias de identidad, intrínsecas y extrínsecas (éste / tal vocablo). Y referencias de no identidad, intrínsecas y extrínsecas (algunas / el antiguo)».

Bibliografía: Gramática Española, I, p. 330.

Referencia inconceptual. «Los demostrativos neutros esto eso aquello se emplean en un género de referencia objetiva y anafórica que podríamos llamar inconceptual para señalar no sólo a las cosas y aun a las personas, [...] sino además a situaciones, ideas, actos y muy especialmente a enunciados complejos acerca de los cuales no es fácil elaborar prontamente un concepto nominal: Pero esta es gente así; quiere divertirse a su gusto y quiere que no se sepa, y e s o cuesta dinero [...]. Es, por consiguiente, un instrumento cómodo en el lenguaje y de aquí la abundancia de su empleo en la conversación y la fuerza de su expresividad».

Bibliografía: Gramática Española, I, p. 251.

Signo fraccionado. Salvador Fernández Ramírez toma de Bally el concepto de «signo fraccionado», el cual - aclara - es el que «tiene significación en su conjunto (es a saber, la locución) y no en cada uno de sus componentes: el vulgo sencillo y a l a b u e n a d e Dios».

Bibliografía: Gramática Española, I, p. 165.

Sustantivo. «Jespersen - hemos visto nosotros - llama nombres sustantivos a los que funcionan ordinariamente como término principal o primario».

Bibliografía: Gramática Española, I, p. 98.

Término inmediato. «Entendemos aquí por término inmediato - escribe en un momento SFR - el complemento, directo o indirecto, que es pronombre personal y no va asociado a complementos directos de cosa. Por lo tanto no sólo el me de me quieren, sino el de me preguntan».

Bibliografía: Gramática Española, 4,p. 116.

Términos primario, secundario y terciario. Salvador Fernández escribe así acerca de los denominados tres órdenes de la rección: «Desde el punto de vista lógico de la subordinación y según el grado en que ésta se realiza, Jespersen distingue en una combinación como muy buen día tres órdenes de elementos que él denomina principal (día), adjunto (buen) y subjunto ( secundario y terciario) y llama nombres sustantivos a los que funcionan ordinariamente como término principal o primario, adjetivos a los que funcionan ordinariamente como elemento adjunto o secundario. Cuando el adjetivo es empleado como término primario decimos que hay sustantivación». «El término secundario - digamos el adjetivo- (añade en otra parte) es el más extenso por su significación, lo que no impide que especifique y delimite el término menos extenso, el término primario (digamos el sustantivo)». 
Jespersen — a quien se remite nuestro autor - había proclamado efectivamente: «Podríamos incluso definir a los substantivos como las palabras que habitualmente figuran como palabras primarias, a los adjetivos como palabras que habitualmente hacen de adjuntos y a los adverbios como palabras que habitualmente hacen de subjuntos». Los Principios... de Hjelmslev se remiten a su vez — en parte - a Jespersen, y escriben: «Nombre $=$ semantema susceptible de morfemas de caso. [...]. Substantivo $=$ semantema que desempeña ordinariamente función de término primario. Adjetivo = semantema que desempeña ordinariamente función de término secundario. Adverbio = semantema que desempeña ordinariamente función de término terciario. Verbo $=$ semantema no susceptible de morfemas de caso. El verbo desempeña siempre función de término secundario».

Bibliografía: Gramática Española, I, p. 98, y Gramática Española, 1, 284; Jespersen, La filosofía de la gramática, p. 103; Principios..., pp. 334-335. Puede verse la glosa de A. Llorente, Teoría de la lengua..., pp. 121-127.

Transitivo, verbo. «Se dice que un verbo, en todos o en uno de sus usos o significados es $\mathrm{t} r$ a n s i t i v o cuando se construye o puede construirse con un complemento directo».

Bibliografía: Gramática Española, 4, p. 149.

Tratamiento. Hay un uso idiomático «que consiste en aludir de manera constante al destinatario de nuestro discurso con una u otra forma verbal y pronominal según la relación social en que él y nosotros nos hallamos. Este fenómeno es conocido con el nombre de $\mathrm{t} \mathrm{r}$ a $\mathrm{t}$ a $\mathrm{m}$ i e $\mathrm{n} \mathrm{t}$ o [y supone ...] la existencia de varias maneras posibles de apelación, previamente establecidas y aceptadas por la colectividad».

Bibliografía: Gramática Española, 4, p. 58.

Voz reflejo-intensiva. «La acción reflexiva, con los verbos de 'beber', 'comer' y 'gozar', supone el hecho de que la masa o el objeto significado por el complemento directo es ingerido de una manera total y completa por una persona. Esto es, al menos, lo que daríamos a entender si dijéramos [...] Nos podemos beber [el agua magnífica de la fuente...]. Podemos hablar, por consiguiente, en estos casos de una voz r e f l e j o - i n t e n s i v a».

Bibliografía: Gramática Española, 4, p. 396.

$$
* * *
$$

Añadimos a la anterior exposición tres entradas al DLEE para una de las cuales hemos compuesto un comentario más amplio; si las anteriores pertenecían todas a Salvador Fernández Ramírez, las presentes se remontan a Menéndez Pidal y a otros autores de su escuela.

\section{BIBLIOGRAFÍA MENCIONADA A CONTINUACIÓN}

ABAD, Francisco: Historia general de la lengua española, Valencia, Tirant lo Blanch, 2008. Encina, Juan del (1991): Teatro completo, ed. de Miguel Ángel Pérez Priego, Madrid, Cátedra. 
LAPESA, Rafael, ed. (1974): Juan de Valdés, Diálogo de la lengua, Zaragoza, Ebro, sexta edición. LÁZARo CARRETER, Fernando (1971): Lengua Española, I, Salamanca, Anaya.

MENÉNDEZ PidAL, Ramón (1962): «Sevilla frente a Madrid. Algunas precisiones sobre el español de América», en el Homenaje a André Martinet, Universidad de La Laguna, pp. 99-165.

- (1933): «El lenguaje del siglo XVI», Cruz y Raya, 6, 15 de Septiembre, pp. 7-63.

- (2005): Historia de la lengua española, Madrid, Fundación Ramón Menéndez Pidal, vol. I.

Vicens Vives, Jaime (1940): Política del Rey Católico en Cataluña, Barcelona, Destino.

- (1944): Mil figuras de la historia, Barcelona, Gallach, II.

- (1956): Els Trastàmares, Barcelona, Ed. Vicens-Vives.

\section{Evolución del lenguaje y voluntad de los hablantes}

Menéndez Pidal estampa - al venir refiriéndose a los años de los Reyes Católicosuna consideración que acaso no debe tomarse tal cual; escribe así: «Si el olvido de la Edad Media y el gusto neológico hubieran proseguido desde tiempos de Santillana como prosiguió en Francia, el Poema del Cid sería tan incomprensible para el español de hoy como lo es la Chanson de Roland para un francés moderno. Pero el español fue en general menos evolutivo que el francés» (2005: 689). Efectivamente nuestra lengua patrimonial ha resultado menos evolucionada que el francés, pero el gusto neológico no explica por sí mismo el más alto grado evolutivo de la lengua francesa, ni explica que el texto al que él alude sea difícil para un francés de hoy.

\section{Giro más amplio en la vida del idioma [español], el}

Don Ramón hace uso de esta fórmula verbal para hacer referencia a lo acaecido a la lengua patrimonial hacia fines de los tiempos medievales. Al llegar a la fecha de 1474 en su aludida Historia de la lengua..., don Ramón estima que se llega a «una nueva edad, la del español áureo o de los llamados siglos de oro, nuevo tipo de lengua y de literatura». En efecto desde hacia fines del Cuatrocientos se llega a una nueva situación idiomática con la gran expansión del castellano, y las letras bellas resultarán distintas: Garcilaso, otros modos en la prosa, etc.; no obstante, cabe decir que a esa lengua es mejor identificarla en tanto la propia del siglo XVI y del siglo XVII que como «áurea», ya que el hablar ordinario no es nunca áureo: esta calificación estética puede aplicarse nada más que al idioma artístico de parte de tales centurias. Desde luego hace bien don Ramón en delimitar uno de los siglos aludidos del otro, ya que poseen consistencia diferenciada: el prof. José María Jover por ej. sitúa entre las fechas aproximadas 1480-1580 la cultura del Renacimiento en España, y entre las de 1580-1680 nuestra cultura del Barroco, y se trata desde luego de fases de lo histórico diferenciadas en su articulación sucesiva, como empezaron a ver quizá los primeros los estudiosos que tenían formación en Historia del Arte (Emilio Orozco, etc.); no creemos adecuada la idea de una edad renacentista de gran amplitud cronológica, tal como defiende aún Antonio García Berrio sin tener en cuenta - al parecer - cómo la mejor historiografía tiene bien establecido que Renacimiento y Barroco constituyen fases A y B de lo histórico.

Por otra parte cabe decir que según nuestro análisis, los años que van de 1474 a 1492 constituyen la segunda mitad de una época que hemos delimitado en la historia del 
idioma de entre 1454 y ese 1492, ya que los hechos nuevos y las rupturas se acumulan más bien hacia la década última del siglo y los años posteriores; el propio Menéndez Pidal pensó en un primer momento - el año treinta y tres - en la relevancia de la fecha del 92, pero algo más tarde, al redactar la Historia de la lengua española -e impulsado quizá (entre otras cosas) por su nacionalismo castellanista - , enfatiza más sobre la fecha de 1474 en que comienza el reinado de Isabel y cuando Fernando pasará pronto a ser monarca castellano efectivo (Vicens, 1944: 206a; cfr. Vicens, 1956: 236-240), e interpreta los datos en el sentido de que con Fernando e Isabel la comunidad política «alcanza su más alto punto de interna perfección y externo desarrollo»; de hecho el propio Jaume Vicens estimó que el hecho más significativo del reinado de los monarcas católicos fue el de «la conjunción de los dos [E]stados peninsulares más poderosos en un complejo político llamado a grandes empresas: el Estado español» (1940: 28).

Estamos por tanto ante una zona de fechas en las décadas finales del Cuatrocientos e inicios del Quinientos en que sucesivos hechos confluyentes determinan mucho la trayectoria de los idiomas peninsulares durante varias centurias: «el idioma sufre ahora en sus rumbos - vemos que manifestaba don Ramón - el giro más amplio y fuerte que en mil años de vida ha experimentado». Don Ramón vivió antes que nosotros, pero como en nuestros días se sabe que las «Glosas Emilianenses» son posteriores a lo que se creía, cabe estimar con él que la lengua patrimonial tiene cerca de mil años — dicho desde luego de manera simplificadora, aproximada y para entendernos - , y que en efecto el giro más amplio experimentado en su historia externa es el que acaece hacia 1492, o sea cabe añadir - hacia mitad de su trayectoria o realidad histórica. Y prosigue Menéndez Pidal (2005: 669-670): «El advenimiento de los Reyes Católicos unifica definitivamente los dos grandes dialectos afines, castellano y aragonés, que seguían caminos separados; hecho de tal importancia que necesitamos ascender al siglo XIII para hallar otro semejante en la unificación del castellano y el leonés bajo Alfonso el Sabio»; varias veces se ha recordado que efectivamente que León se castellaniza de manera profunda desde 1230, y Aragón culmina análogo proceso en los años del reinado de su monarca Fernando II. Según la estimación pidalina, los varios dialectos peninsulares han concurrido para formar «el tipo lingüístico español» (2005: 695); es una idea compartida por el maestro y por García de Diego, y sobre la que ambos debieron estimularse mutuamente.

En el Doscientos había ocurrido ciertamente que la unión ya definitiva de las coronas leonesa y castellana contribuyó - dicen las palabras de don Ramón al respecto- «a la más rápida compenetración de los dos dialectos», de manera que «cuando se produce la conquista de Andalucía y Murcia [...] la repoblación del Sur se hace por gentes mezcladas de los dos reinos, sin separación entre gallegos, leoneses y castellanos, mezcla favorable a los influjos dialectales que integran la lengua común» (2005:490-491).

Menéndez Pidal tenía así por seguros los dialectalismos varios que se presentan en los códices regios de la General Estoria: llamer 'lamer'; piedade (con vocal final no apocopada); interpolaciones entre el pronombre átono y el verbo («vos esta mi carta aduze»); ... (2005: 532-533). Y debe añadirse que en el tiempo que transcurre entre el rey Alfonso y hasta por lo menos Juan de Valdés (cerca de tres centurias) - es otra observación pidalina en un distinto escrito suyo , «Sevilla frente a Madrid» (1962: 99) —, Toledo define el prototipo del castellano ya que permanece una misma fonética: el español moderno surgirá con los cambios que se afirman y generalizan según avanza el Quinientos. Cum- 
plidos ya tales cambios quedará establecido en lo fónico el español «moderno», que en este sentido no debe llevarse - así lo creemos - hasta la fecha tardía de hacia 1700; tampoco resultan adecuadas las equívocas palabras del prof. Fernando Lázaro cuando indica que en los tres primeros cuartos del siglo XV el idioma castellano fija cada vez más su perfil moderno (1971: 127).

El amplio giro en la situación idiomática del entonces dialecto castellano a fines del siglo XV consta por tanto de su llamada unificación con el dialecto aragonés, y además por otros hechos bien visibles, recordados por varios autores: obviamente los descubrimientos geográficos; y asimismo el conjunto de las empresas políticas exteriores; la expulsión y dispersión de los judíos y con ellos la historia del judeoespañol; el principio de una cierta uniformación de la lengua escrita que había traído la imprenta; la generalización del uso literario del castellano por autores de fuera de Castilla, en regiones geográficas en las que el vernáculo hablado era otro código (Portugal, Cataluña, etc.).

Don Ramón simboliza asimismo el giro experimentado por el castellano en los años siguientes a 1474 en las «Coplas» manriqueñas, ya que quebraban la estilística que había estado tan presente hasta entonces en la literatura más culta durante el Cuatrocientos: según se ha dicho, Jorge Manrique escribe en manera elegante pero no extravagante (de ruptura marcada con las normas del sistema); atrás empezaba a quedar el retoricismo que en realidad minusvaloraba el romance vernáculo, según le ocurrió a Juan de Mena, etc.

En estos decenios en torno a 1500 de una nueva unificación entre los dialectos peninsulares históricos, el dialectalismo aragonés - según decimos - desaparece, y Aragón se convierte en centro de producción literaria en lengua española; por su parte el antiguo reino leonés aporta al español común - recuerda el hecho bien sabido don Ramón - el habla arcaica de sus aldeas como tipo de lengua villanesca en la literatura (el mismo Juan del Encina, Lucas Fernández): esa habla refleja literariamente los bables leoneses : «llugar»; «mudancia»; «obrigar»; ... (2005: 698 y 701). Yendo al teatro de Juan del Encina, encontramos efectivamente en sus piezas formas como «prazer», «perlabrado», «greja» 'iglesia', «lle» 'le', «ño» 'no', «diabro», «San Pabro», «habro», «llabro» 'labro', «empraziar» 'emplazar', etc. (Encina, 1991: 98, 99, 195, 196, 221, 223, 224, 231; la forma «greja» es dialectalismo estilizado poéticamente, un poco lo que Amado Alonso llamaba «prevaricación idiomática»).

Según el propio sentimiento idiomático pidalino, los libros de caballerías (hay que entender que algunos) «daban elegancia a lo mejor de la lengua medieval» (2005: 814); no obstante el Amadís (1508) le pareció ya antiguo a Juan de Valdés - hecho que a su vez no le pasó inadvertido a Menéndez Pelayo-. En efecto Valdés proclama por ej.: «No me suena bien viniera por avía venido, ni passara por avía passado; el editor Lapesa por el que citamos, anota que el sentido de pluscuamperfecto se conserva en Galicia y Asturias, y - tal como es bien sabido - se conserva desde luego en el español escrito culto de hoy (Lapesa, 1974: 124).

\section{Preclásico, español}

Tampoco la lengua de los siglos XVI y XVII debe denominarse «clásica» tal como muchas veces se hace hoy día, ya que sólo el registro artístico - no el hablar ordinario- 
puede ser clásico; tampoco debe hablarse sin más de los años 1554/1616 como de los de «culminación de la época clásica», según establece el propio don Ramón en la Historia... llevado de su gusto por la claridad elocutiva y el gusto en general por el Quinientos que le venía de Menéndez Pelayo; de su lado el joven Rafael Lapesa que en 1942 edita por vez primera su propia Historia de la lengua y que tenía recientes las enseñanzas del «Centro de Estudios Históricos», rotula asimismo uno de los epígrafes de la obra «el español preclásico (1474-1525)», lo que no aparece ajustado, etc. — sin duda la revolución poética garcilasiana tras 1526 le hace fechar el término de tal denominado preclasicismo en 1525; esa revolución la intuye no obstante al notar en concreto cómo consiste entre otras cosas en que «la serena lentitud del endecasílabo se impone al vivaz ritmo octosilábico y sus abundantes rimas»-.

Hace sólo unos meses - cuando escribimos esto - que se ha publicado nuestra Historia general de la lengua española. De manera breve - volveremos sobre el asunto- podemos hacer algunas adiciones y comentarios.

1. Ya dijimos en sus páginas preliminares que se trataba de una obra con extensión limitada, a pesar de sus 656 páginas: mucha materia ha debido quedar fuera, aunque poseíamos y poseemos lecturas y borradores ya hechos para poder ampliarla; la bibliografía mencionada asimismo ha tenido un límite - lo que ocurre en cualquier escrito de esta clase - , pues ningún estudioso puede racionalmente conocerlo todo o casi todo, y además nosotros no quisimos citar nada de cuyo contenido no nos hubiésemos hecho cargo personalmente y de manera que nos pareciese suficiente. Además ya tenemos indicado que no se trata de una fonética histórica, de una morfología histórica, o sintaxis histórica, etc., y tal cosa explica la ausencia de mención o de aprovechamiento de algunas monografías: por ej., la Historia de la pronunciación de don Amado más sus artículos complementarios (que en otra ocasión deseamos emplear y comentar, ya que se encuentra un tanto olvidada). Lo referido al español en América - salvo una noticia necesaria acerca de los orígenes de ese español- queda pospuesto para otro trabajo monográfico que desearíamos poder llevar adelante: un escrito de Historia integrada del español peninsular y americano.

2. La mención al inicio de la obra del texto de Diego Catalán Lingüística Íbero-Románica. Crítica Retrospectiva (ed. española en 1974), tenía el propósito de que a través de la misma se tuviese acceso a una información crítica acerca de una parte de la bibliografía, sobre todo en aquellas materias en las que carecemos de formación personal específica: Catalán menciona por ej. el análisis «penetrante y ponderad[o]» que del substrato prerromano ha llevado a cabo Craddock (p. 147), y así muchos textos más; nosotros preferimos de momento llevar a síntesis datos más antiguos y otros editados hace muy poco de Menéndez Pidal. Desde luego han de verse de Lingüística Íbero-Románica $\operatorname{los} \S \S 3.5$. y 3.6 . 
3. A nosotros nos parece que algunos capítulos o epígrafes de la Historia de la lengua que escribió don Jaime Oliver Asín siguen teniendo vigencia, y por eso lo tenemos en cuenta. En tanto obra de conjunto existe también -y su mención la añadimos ahorael texto (1936) de William J. Entwistle The Spanish Language, que se ha traducido como Las lenguas de España: castellano, catalán, vasco y gallego-portugués (Madrid, Eds. Istmo, 1995 - reimpresión-). Se trata de un texto con bastantes datos lingüísticos internos; opera no obstante con una idea desorientadora, y es la de que «castellano y español se convierten en sinónimos con el apoyo de las cancillerías y de la floreciente literatura vernácula (siglos XII y XIII) . [...] En el siglo XIII [...] el castellano, con ciertos compromisos, se convirtió en la lengua de las cancillerías de España y de la gran prosa literaria» (pp. 137 y 139): ciertamente algunos hechos no son tan tempranos, y la faz dialectal peninsular era mucho más diversificada en ese paso de la Alta a la Baja Edad Media.

En cuanto a la fijación de la ortografía, no deja de advertir con acierto Entwistle cómo la escritura española contemporánea «resulta convencional en relación con la pronunciación de numerosos españoles e hispanoamericanos»: en un cartel hemos podido leer recientemente en Málaga «Patatas frita»y «Pescaito fritos».

El mismo Entwistle aborda la noticia del judeoespañol cuando se refiere a las centurias del XV y del XVI y creemos que así debe hacerse-, y por igual la del andaluz; al español en América le dedica un capítulo conjunto posterior, en el que proclama que «a cada palabra y frase utilizados en el español de América hay que reconocerles carta de naturaleza, y admitirlas como elementos de pleno derecho» (p. 296), lo que no era tan frecuente en 1936. Nuestra idea - tenida en cuenta en la práctica en la Historia general..., es la de que la trayectoria toda del idioma debe periodizarse en épocas de hacia un tercio de siglo, y que en cada momento debe integrarse lo que ocurre en el español peninsular y en el americano, y en el de otras partes del mundo.

4. Nuestro colega norteamericano Steven Hess - los hispanistas del extranjero pertenecen a otra tradición cultural y poseen a veces otras percepciones - , nos sugiere incorporemos a la historia de la lengua alguna mención al romancero. Remitimos así a los dos volúmenes de don Ramón Menéndez Pidal Romancero Hispánico (Hispano-portugués, americano y sefardí) (Madrid, segunda ed., 1968), y en concreto:

a) Para la propia palabra castellana romance: vol. I, pp. 3-8.

b) Sobre el estilo tradicional: I, cap. III, en el que leemos: «La principal figura retórica usada en el estilo tradicional es la repetición. [... Esa reiteración...] es sin duda lo que más distingue el estilo épico-lírico de los romances respecto al estilo propiamente épico de las gestas».

c) Sobre la métrica de los romances: I, cap. IV, en el que también se trata de la -e asonántica o paragógica del romancero y de la lírica popular, - e asonántica «mal llamada paragógica, en realidad -e etimológica y a veces ultracorrecta».

5. El mismo prof. Hess nos sugiere que - aunque no tratemos de fonética histórica por sí misma - mencionemos el trabajo de José del Valle El trueque $s / x$ en español antiguo. Aproximaciones teóricas, Tübingen, Max Niemeyer, 1996. 
6. Por inadvertencia nuestra no figura acerca del corónimo «Andalucía» la mención de Antonio Domínguez Ortiz, La identidad de Andalucía, Universidad de Granada, 1976.

$* * *$

Se nos ha pedido asimismo que demos la referencia concreta de algunos escritos propios que resulten pertinentes, anteriores a esta Historia general... y convergentes con ella: muchos de sus datos hubieran pasado a sus páginas de no estar ya publicados. Escogemos algunos, dado que - en efecto- lo escrito en un momento por un mismo autor nada más se entiende y cobra sentido que en el contexto de todas las otras cosas dichas por él.

A) - Noticia de la lengua española, Madrid, Cátedra de Lingüística General de la UNED y Distribuciones EDAF, 1983. Poema inicial de Jorge Guillén y Prólogo por Amando de Miguel.

- «El lenguaje del siglo XIX. Problemas que plantea su estudio», Serta gratvlatoria in honorem Juan Régulo, Universidad de La Laguna, 1985, I, pp. 27-41.

- «La lengua española «moderna»: la lengua del siglo XX», In memoriam Inmaculada Corrales, Universidad de La Laguna, 1987, I, pp. 13-26.

— «Notas sobre la disciplina «Historia de la lengua española"», Anuario de Letras, XXIX, 1991, pp. 9-15.

— «El «español primitivo»: concepto y algunas cuestiones que plantea», Actas del II Congreso internacional de Historia de la lengua española, Madrid, Pabellón de España S. A., 1992, II, pp. 519-528.

- «Ejemplos y muestras de método en Historia de la lengua española», Antiqva et Nova Romania, Universidad de Granada, 1993, I, pp. 3-17.

— «Hacia una Historia de la lengua española “moderna” (1713-1973)», Didáctica (Universidad Complutense), 6, 1994, pp. 13-21.

- «Problemas en historia de la lengua española (1250-1713)», Estudios en homenaje al prof. Fernando González Ollé, Pamplona, EUNSA, 2002, pp. 21-39.

- «Aspectos de la lengua española (siglos XV y XVI)», en el Homenaje al profesor Estanislao Ramón Trives, Universidad de Murcia, 2003 [2004], I, pp. 51-67.

— «Galicismos (y otras cuestiones) en la lengua española de 1680-1713», CAUCE, 29, 2006, pp. 7-15.

B) - «El lenguaje del siglo XVI», Estudios románicos dedicados al profesor Andrés Soria Ortega, Universidad de Granada, 1985, I, pp. 3-15.

- «Conciencia lingüística y estilo de Alfonso X», en F. Carmona y F. J. Flores, eds., La lengua y la literatura en tiempos de Alfonso X, Universidad de Murcia, 1985, pp. 9-24.

— «Retórica de Góngora en las Soledades», en la obra colectiva Crítica semiológica de textos literarios hispánicos, Madrid, CSIC, 1986, II, pp. 215-229.

- «Ideas sobre la lengua y usos lingüísticos de Clarín», en Clarín y La Regenta en su tiempo, Universidad de Oviedo, 1987, pp. 985-995.

- «Lenguas y estilos medievales: Juan Ruiz», Studia in honorem prof. M. de Riquer, Barcelona, Quaderns Crema, 1987, II, pp. 237-254. 
- «Apuntes sobre la lengua y el estilo de Miguel Delibes», C. Cuevas, ed., Miguel Delibes, Barcelona, Ed. Anthropos, 1992, pp. 215-224.

«La lengua literaria y el pensamiento lingüístico de Valle-Inclán», en M. Aznar-J. Rodríguez, eds., Valle-Inclán y su obra, Universitat Autònoma de Barcelona, 1995, pp. 79-86 (en colaboración).

- «Lengua o estilo de Jaime Gil de Biedma», Actas del Congreso «Jaime Gil de Biedma y su generación poética», Zaragoza, Diputación General de Aragón, 1996, I, pp. 111-120.

- «Lengua y estilo de La ciudad y los perros», en Conversación de Otoño. Homenaje a Mario Vargas Llosa, Murcia, Fundación Cultural CAM, 1997, pp. 161-168.

- «La trayectoria de la lengua y el estilo de Gabriel García Márquez», Actas del Congreso «Gabriel García Márquez», Universidad de Zaragoza, 1997, pp. 161-168.

- «Problemas de periodización y caracterización en historia de la lengua literaria española» [(I)], Revista de Filología Románica [de la Universidad Complutense], 15, 1998, pp. 13-33.

- «Problemas de periodización y caracterización en historia de la lengua literaria española (II)», EPOS, XIV, 1998, pp. 493-513.

- «Otras notas sobre la lengua y el estilo de Gabriel García Márquez», en Estudios sobre el español de América (=Actas del V Congreso internacional de «El español de América»), Universidad de Burgos, edición electrónica, 2001, colaboración 002.

- «Sobre la lengua literaria de Benavente y de la Edad de Plata», Cuadernos del Lazarillo, 26, 2004, pp. 30a-33b.

C) - «Sobre el concepto literario [y la lexía] de "Siglo de Oro": su origen y su crisis», Anuario de Estudios Filológicos [de la Universidad de Extremadura], IX, 1986, pp. 13-22.

— «Semiótica y "Barroco": un concepto y una palabra», EPOS, VI, 1990, pp. 225 241.

- «Para la semántica y el léxico de descubrir e inventan», Investigaciones Semióticas, IV, Madrid, Visor, 1992, II, pp. 855-863.

- «Sobre la bohemia», estudio incorporado al fascículo Literatura y Arte: Lorca, Buñuel, Picasso, Madrid, UNED, 1995 (D. L. M-28.850-1995) [incluye un análisis de las voces bohemios y golfos más unas «Conclusiones de historia léxica española»].

— «Schopenhauer y el joven Baroja (El léxico del dolor y de la compasión)», Anales de Literatura Española [de la Universidad de Alicante], 12, 1996, pp. 129-137.

- «Incorporación del vocabulario de la informática a los Diccionarios», en Literatura y multimedia, Madrid, Visor, 1997, pp. 211-217.

- «Para la historia de las palabras semántica y semasiología en castellano», Actas del IV Congreso Internacional de Historia de la Lengua Española, Universidad de La Rioja, 1998, pp. 15-21.

- Cuestiones de lexicología y lexicografía, segunda ed. reformada y muy ampliada, Madrid, UNED, 2000 [las ediciones segunda, tercera y tercera reformada de esta obra presentan todas textos nuevos, y no incluyen distintas páginas de la primera].

— «Otros datos sobre la trayectoria de la palabra "literatura" en castellano», SIGNA, 10, 2001, pp. 365-373. 
— «Lengua, cultura y diccionarios», en R. Senabre, ed., El lenguaje de la literatura, Salamanca, Almar, 2003, pp. 11-34.

— «"Retórica». Apuntes sobre la palabra y la cosa», SIGNA, 14, 2005, pp. 13-36.

— «Notas léxicas: "siglo de oro liberal", "Edad de plata", "generación del 27"», en Palabras, norma, discurso en memoria de Fernando Lázaro Carreter, Universidad de Salamanca, 2005, pp. 39-48.

— «Las denominaciones "generación del 27" y "generación del 36"», Boletín de la Fundación Federico García Lorca, n 37-38, 2007, pp. 113-130.

— «Las lexías «generación de 1898» y «generación de 1914», Estudios literarios in honorem Esteban Torre, Universidad de Sevilla, 2007, pp. 735-746.

— «"Siglo liberal”, "generación del 27”, y otras lexicalizaciones conexas», en Del Siglo de Oro y de la Edad de Plata. Estudios [...] dedicados a Juan Manuel Rozas, Cáceres, Universidad de Extremadura, 2008, pp. 181-196.

- «Las expresiones léxicas "Edad Moderna", "Edad Contemporánea”, "siglo liberal", y otras conexas», Historia, política y cultura. Homenaje a Javier Tusell, Madrid, UNED, 2009, II, pp. 247-264. 